\title{
The German National Educational Panel Study: a wealth of potential for research in school-to-work transitions
}

\author{
Kathrin Leuze \\ Social Science Research Centre Berlin \\ kathrin.leuze@wzb.eu \\ Wolfgang Ludwig-Mayerhofer \\ University of Siegen \\ Heike Solga \\ Social Science Research Centre Berlin
}

(Received November 2010 Revised July 2011)

\begin{abstract}
Advanced societies in general, and Germany in particular, are faced with many unanswered questions regarding their vocational education and training (VET) systems in terms of access, outcomes, and individual skill formation. Is VET still capable of providing the skills necessary for a successful transition into the labour market? How can low-achieving youth enter and finish vocational training? How do cognitive and non-cognitive competencies develop in the course of VET? At the moment, however, we do not have sufficient longitudinal data to give profound answers to these and other questions. The German National Educational Panel Study (NEPS), launched in 2008 and funded by the German Federal Ministry of Education and Research, will provide unique longitudinal data on life histories in combination with measures on competence development over the life course. Within NEPS, the so-called Stage 6, 'Vocational Education and Training and Transitions into the Labour Market', is devoted to collecting and providing longitudinal data on the transitions of young people from secondary schools into the labour market. In this paper, we shall describe the main features of the survey design of Stage 6 and discuss the research potential offered by this new type of data.
\end{abstract}

Keywords: Education, school-to-work transition, Germany

\section{Introduction}

The competitiveness and performance of national economies are inherently linked to the productivity of their workforce. Changes in labour markets and in the world of work imply an increase in the level of average skill requirements - coupled with the constant risk of a polarization of skills - as well as fast turnovers in the content of skills. Schooling and initial vocational and professional training have maintained their primary significance for occupational careers; however, the content and timing of schooling and training are under pressure to change (Mayer and Solga 2008).

For a long time, the so-called German 'dual system' has attracted much attention in international debates. It has been seen as one of the skill formation systems (or skill regimes) that have 'appeared capable of reconciling high wages with high productivity via high skills and high valueadded production' (ibid 8). Accompanied by compressed wage differentials, it has still been regarded as capable of integrating less educated youths into procedures enhancing skill formation (Streeck 1989; Reich 1991; Culpepper and Finegold 1999; Estevez-Abe, Iversen and Soskice 2001). The ability of the German vocational education and training (VET) system to adapt to new technological and market conditions has, however, increasingly been called into question (Herrigel and Sabel 1999; 
Baethge 2000; Baethge, Solga and Wieck 2007; Culpepper and Thelen 2008). Is VET still capable of providing the skills necessary for a successful transition into the labour market? How is it possible for low-achieving youth to enter and finish vocational training? How do cognitive and noncognitive competencies develop in the course of vocational education and training?

For some of these questions, we have (preliminary) answers; for others, however, we still lack the necessary data and interdisciplinary research efforts. During the past 20 years, longitudinal datasets covering early labour-market experiences have become widely available.' However, these large-scale datasets do not provide sufficiently detailed information to allow for valid conclusions about the factors that shape school-towork transitions and about the consequences these transitions may have. More detailed data on competencies, educational biographies, and the manifold transitions in young adulthood are needed, for example. Some specialized studies on school-to-work transitions do include a broader range of variables, but these are limited in their potential for generalization because of sample restrictions in terms of the region(s) or social group(s) covered. ii Finally, large-scale comparative studies on the individual competence attainment of children, adolescents, and adults have been conducted in the past decade, but as cross-sectional surveys, they cannot provide information on educational pathways, competence development, and the influence of these two factors on job placement and other labour market outcomes. iii

A longitudinal, prospective panel survey of individuals' educational and environmentally embedded life histories that simultaneously collects data on cognitive competencies, non-cognitive capabilities (such as personality traits, learning strategies, values, interests, motivations, attitudes), as well as on decision-making processes will provide a unique opportunity for studying school-to-work transitions in more detail. The German National Educational Panel Study (NEPS) is a new longitudinal study designed to investigate the relationships between educational biographies, learning environments, competence development and returns to education over the life course for nearly all age groups. Within NEPS, the so-called Stage 6, 'Vocational Education and Training and Transitions into the Labour Market', specifically collects and provides longitudinal data on school leavers' transitions into the labour market. It opens up the opportunity to examine young people's motivation and competence endowment, their decisions and constraints concerning participation in VET, the information and support they may receive from families and other social networks, or the learning environments they encounter in companies and vocational schools. With this type of innovative data, it will become possible to answer many of the open questions on school-to-work transitions, both for the specific case of Germany and with regard to cross-national comparisons.

Since NEPS data collection only started in late 2010, the goal of this paper is not to provide initial answers to the above-mentioned questions. Rather, it aims to introduce the study design and research potential of NEPS Stage 6 to those who may be interested in either working with this dataset in the future, or in using its design in other empirical studies, such as cross-national comparisons. NEPS is based on a complex research design; therefore, we shall begin by presenting a (necessarily brief) overview of NEPS as a whole, before outlining the specific survey design and research potential of NEPS Stage 6. First of all, however, we shall provide some background information on the German VET system, to facilitate a better understanding of the challenges and potential of this unique longitudinal study.

\section{Vocational Education and Training (VET) in Germany}

The German VET system is characterized by a number of special features. In contrast to countries such as the United States, where young people acquire general, non-specific credentials mostly through schools and colleges, and job-related skills through on-the-job-training, about 60 per cent of German adolescents leave school comparatively early in order to acquire occupation-specific credentials through a period of VET, typically lasting three years. This arrangement is based on the rigid tracking of pupils after four to six years of primary schooling into three types of secondary schools: lower secondary schools (Hauptschule and special education schools for youths with disabilities, lasting nine or ten years), middle secondary schools (Realschule, lasting ten years), and upper secondary schools (Gymnasium, lasting 12 to 13 years). Pupils who leave lower or middle secondary school 
normally head for VET, whereas those who complete Gymnasium are entitled to enter university and actually do so in large numbers.

VET can take place either by way of an apprenticeship in the so-called 'dual system' or in full-time vocational schools. The dual system of vocational training combines an apprenticeship in a company with part-time schooling. School-based VET programmes provide training through full-time schooling, combined with periods of practical training, mainly via internships. Both company- and school-based programmes lead to nationally recognized occupation-specific VET certificates. The dual system trains young people for manufacturing and industry occupations and some of the white-collar occupations (such as commercial, retail, and administrative occupations), whereas full-time school-based VET programmes prepare trainees for personal service occupations (such as nurses, midwives, medium-level care professionals, kindergarten teachers, and social workers) and medium-level technical occupations (such as dental technicians). A few exceptions notwithstanding, company- and school-based VET programmes thus are not alternative pathways leading to the same occupations but pathways segmented by occupations (and mostly by gender, i.e. by male and female-dominated occupations).

What looks rather clear in principle - a segregated system of compulsory schooling with graduates below the Gymnasium level entering either the dual system or a full-time school-based VET programme - has in fact become much more complicated and blurred in recent decades. For example, Gymnasium graduates have increasingly started to opt for VET below the university level. Combined with a decrease in the number of apprenticeships offered by companies, not compensated for by increases in the school-based VET system, this development has resulted in the enormous expansion of what is called the prevocational transition system, in which young people are either taught basic occupational skills or acquire additional secondary school education in courses typically lasting one year. Thus, making a direct transition into VET after completing grades 9 and 10 is no longer feasible for many of today's youth in Germany (Baethge, Solga and Wieck 2007; Dietrich et al 2009).

To complicate things even more, some Hauptschule or Realschule graduates choose to prolong their general schooling in an attempt to obtain a higher-level school certificate to become more competitive in the search for an apprenticeship, or to be entitled to enter university. In addition, about 20 per cent of apprentices terminate their contract prematurely, typically to start anew in a different occupation or with a different company. Finally, some students quit university prematurely to continue their education in the VET system, whereas others enter university after completing a VET programme. For many school leavers, therefore, the transition from school to work is a prolonged and risky period of 'passing' or 'muddling through' the VET system, of eventually obtaining one or more vocational education certificates, and of finally launching their career (Eberhard, Krewerth and Ulrich 2006). Furthermore, school leavers' multiple transitions do not always follow a 'coordinated' sequencing pattern in terms of educational biography or skill development (Buchmann 1989).

Yet, we have little knowledge about whether and, if so, why, different pathways result in different competence and general employment skills endowments. It is of high importance, therefore, to collect data that captures all of these different pathways from school to work, and that, at the same time, provides multi-time measurements of young people's (cognitive and non-cognitive) competencies.

\section{Research Design of Stage 6: Vocational Training and Education and Transitions into the Labour Market}

One basic prerequisite for adequately dealing with the complexities of current transition patterns is using a large sample, combined with a sound strategy for sampling and minimising (selective) panel attrition. These aspects will be addressed in the following, preceded by a short introduction to the overall NEPS design.

\section{Study design of NEPS: a brief overview}

NEPS as a whole starts with six different cohorts (Blossfeld, Schneider and Doll 2009, 26-29): (1) newborns (2) kindergarten children at the age of four (3) students at the beginning (fifth graders), and (4) shortly before the end of lower secondary schooling (ninth graders) (5) first-year college and university students (6) adults aged 23 to 64 . Figure 1 shows how each of the starting cohorts moves 
through a variety of so-called 'educational stages' over the life course. These educational stages include the distinct stages of formal education, as well as the preceding and subsequent stages of early childhood education at home and in kindergarten on the one hand, and adult education and training on the other.

For each of the educational stages, one research team of specialists in the respective area has been formed. With regard to the starting cohort of ninth graders, it is of interest to note that subsequent trajectories are sub-divided into two distinct educational stages of upper secondary education, in accordance with the German education system. Stage 5 surveys trajectories within general schooling (i.e. Gymnasium), whereas Stage 6 collects information on all school leavers transitions to VET and into the labour market (until the age of 24). That is, if a respondent leaves Gymnasium prematurely, s/he will continue to be followed just like any other school leaver. In other words, although specialized research teams develop questionnaires and tests tailored to each specific educational stage, the overall research design provides opportunities for following all members of all samples, and for administering the instruments that are appropriate to the specific circumstances of each individual. Thus, Figure 1 depicts the transition, from school to VET and on to work, in a highly idealized fashion.

Figure 1. The Multi-Cohort-Sequence Design of the NEPS

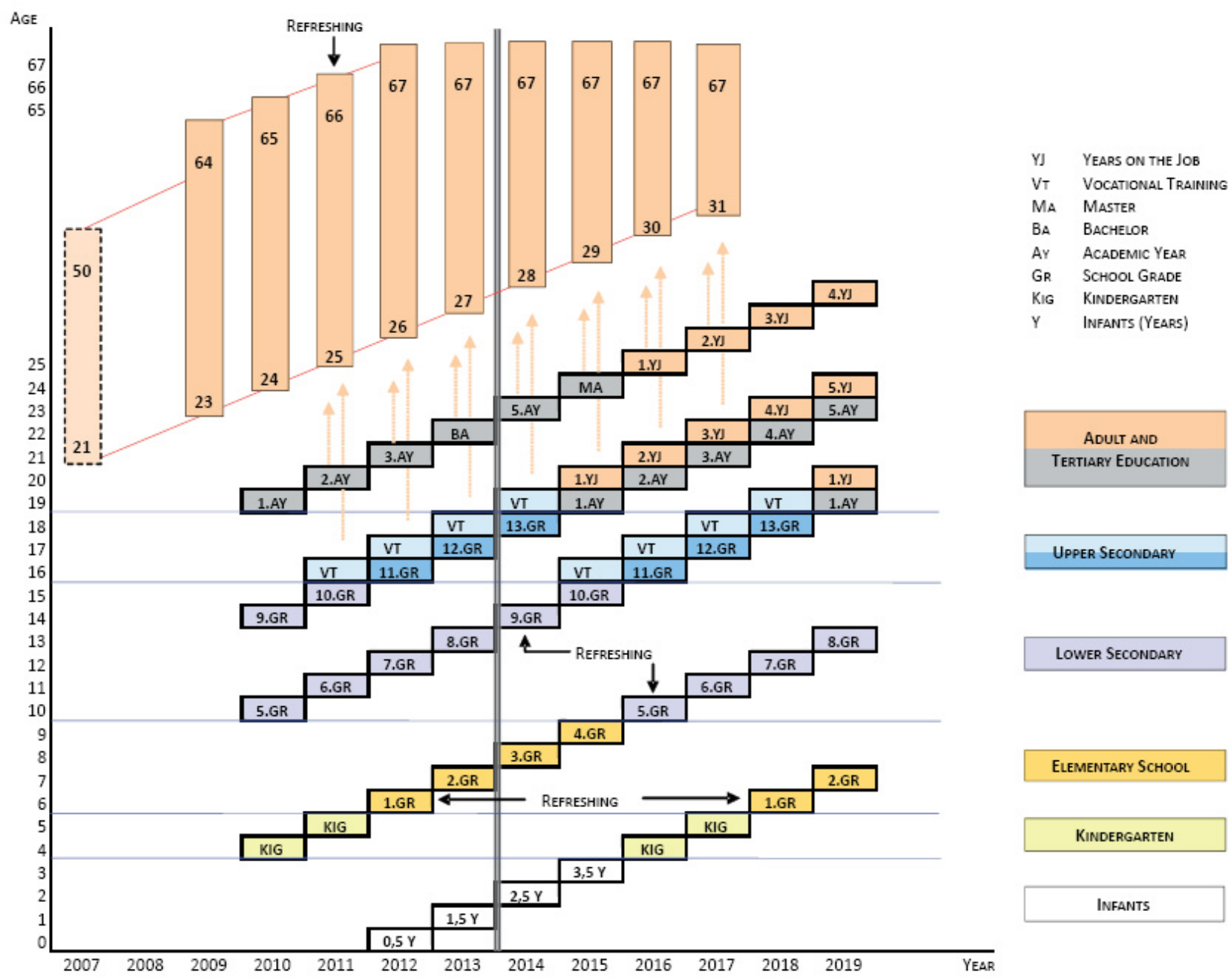

(Source: Blossfeld, Schneider and Doll 2009, 28) 


\section{Sampling of NEPS Stage 6}

With a starting sample size of 16,044 ninth graders, Stage 6 will be able to draw on a very high number of respondents for conducting differentiated analyses of school-to-work transitions (see Table 1). All of the target persons are young adults attending grade nine at German secondary schools in autumn 2010 . For the purpose of sampling, the population was stratified by the different types of schools, and an institutionallybased, random sample, using schools as sampling units, was drawn. This clustering of students in classes and schools allows for an analysis of structural and compositional context effects (Blossfeld, Schneider and Doll 2009, p. 27). The response rate of the first wave was 60.5 per cent. This is quite high, considering the fact that students could only be included in the survey if they themselves and their parents signed an agreement to participate in the panel study. ${ }^{\text {iv }}$

Table 1. Sample design and size for NEPS Stage 6, ninth grade (2010)

\section{School type}

Lower secondary schools (Hauptschulen)

Middle secondary schools (Realschulen)

Integrated comprehensive schools (Integrierte Gesamtschulen)

School offering multiple tracks (except the Gymnasium track)

University-preparatory schools (Gymnasium)

Special education schools (for students with learning disabilities)

\section{Number of schools}

181

104

55

55

149

105

\section{Number of ninth graders}

3,688

3,174

1,654

1,154

5,211

1,163
Lower secondary schools (Hauptschulen) and integrated comprehensive schools (integrierte Gesamtschulen) are oversampled in order to facilitate the study of the various trajectories of disadvantaged youth and their outcomes, as well as the problems of migrant youth (who attend these two school types in disproportionate numbers). In addition to pupils from all regular school types, NEPS includes a considerable number of pupils enrolled at special education schools with an emphasis on learning disabilities - a unique survey feature for Germany and many other countries. The segregation rate of disabled children is still very high in Germany (Powell 2009). About 90 per cent of the children classified as disabled attend one of the ten school types for children with special needs (of these, 50 per cent attend schools for children with learning disabilities). These children account for 6 per cent of all school leavers and for about half of those leaving school without a school degree.

\section{Follow-up, testing, and surveying of participants}

In grade nine, pupils are surveyed and tested by means of paper-and-pencil questionnaires (PAPI).
NEPS not only surveys educational trajectories, certificates, and grades as educational outcomes, but also tests important basic skills - initially (2010) in the first wave (German reading and writing, maths, science and computer skills), again three years later (reading, maths and computer skills), and so forth. This allows for analyzing the extent to which adolescents' various transition pathways have an effect on their competence development upon graduation. In addition, information regarding young people's non-cognitive competencies (e.g. self-efficacy, personality traits), their academic selfconcept, interests, educational and training goals, vocational training plans, decision parameters, social networks, and leisure activities have been collected in ninth grade; some of them will be recollected in regular intervals (in subsequent waves). As a result, a variety of measures for influences on and outcomes of adolescents' future educational and employment trajectories will become available.

Additionally, up until the end of compulsory schooling, parents are surveyed via telephone interviews once every year, to gather first-hand information on pupils and their parents (e.g. about parents' educational aspirations for their children, the ways in which they support their children's 
transition to vocational education and training, or the importance of parents' cultural and social capital for finding an apprenticeship position). Teachers and principals are surveyed, too, in order to get a better understanding of institutional support or barriers for individual transitions from school to VET.

Once participants have left compulsory schooling, they will be tracked individually (Blossfeld, Schneider and Doll 2009, 27). School leavers will be contacted at six-month intervals and questioned in detail via computer-assisted telephone interviews (CATI). The main survey will always take place in the autumn, and will take about 40 minutes. A shorter interview of about 20 minutes will be conducted each spring, mainly to update the longitudinal life history episodes and to record changes that may have taken place. The individual data generated in this way, will be enriched by adding structural information regarding training companies and employers, with the help of register data collected at the Federal Employment Agency, in order to gain information on young people's company-based learning environments.

Young people in Germany can leave school after completing grade $9,10,11,12$, or 13 , and may thus enter Stage 6 at very different points. The first wave of Stage 6, to be conducted in autumn 2011, will include pupils leaving school after completing grade nine. After a loss of 10 per cent due to panel mortality in grade nine, we expect about 18 per cent of ninth graders at regular secondary schools and about 75 per cent of ninth graders at special education schools to actually leave school; these persons will thereafter be tracked individually. The majority of pupils, however, will make the transition to vocational education and training after completing grade ten. Therefore, in autumn 2012, we expect to survey about 70 per cent of the remaining pupils who attended regular schools in 2010 and all remaining pupils from special education schools; by 2014-2015, the entire (remaining) start cohort will have entered Stage 6. Due to the protracted nature of the transition process, entry into the labour market will last until the age of 22 (or until about 2017) for the majority of those not entering university, and until the age of 25 (or 2020) for university graduates.
In order to keep the panel attrition rate low and to avoid attrition selectivity as much as possible, a number of special measures will be applied. First of all, computer-assisted telephone interviews will be conducted in all waves that do not include tests (in those that do, face-to-face interviews will be conducted). Telephone interviews allow for a very high number of attempts to get in contact with target persons. In addition, the fast-growing use of mobile phones (especially among young people) over the last ten years has served to increase respondents' availability, as interviews can be conducted - or at least initial contact can be made even when target persons are not at home. However, respondents not reachable by phone, or unwilling to give a telephone interview, will be contacted by on-site visits of interviewers at the respondents' place of residence, and CAPI (computer-assisted personal interviews) will be conducted with those who agree (about 10 per cent of the sample).

Given that about 20 to 30 per cent of the target persons in NEPS Stage 6 are rather low-achieving youths, we will have to try as best as we can not to overburden them, lest they drop out of the NEPS panel. One way of doing so is, as already mentioned above, to subdivide the questionnaire for each wave into two separate interviews: a short interview in spring and a longer interview in the autumn of each year.

Finally, all of these strategies will be accompanied by target-group-oriented incentives, which consist of fixed monetary rewards for each completed interview, as well as participation in a lottery (with substantial prizes) after completing four interviews. These strategic activities offer a promising approach for achieving the ambitious goals of keeping panel attrition and its selectivity low, and of following participants from secondary schooling to vocational training and from there into the labour market.

Table 2 offers an overview of the survey modes, target population, and survey duration of the first four panel waves up to autumn 2013. The contents of the survey will be explained below, along with information on selected potential research areas of Stage 6. 
Table 2. Research design of NEPS Stage 6

\begin{tabular}{|c|c|c|}
\hline Wave & Target population & Survey mode \\
\hline $\begin{array}{l}\text { First wave } \\
2010-2011\end{array}$ & $\begin{array}{l}\text { Ninth graders, their parents, } \\
\text { teachers, and principals }\end{array}$ & $\begin{array}{l}\text { Classroom PAPI } \\
\text { (survey and tests) }\end{array}$ \\
\hline $\begin{array}{l}\text { Second wave } \\
2011-2012\end{array}$ & School leavers & CATI (survey) \\
\hline $\begin{array}{l}\text { Third wave } \\
\text { 2012-2013 }\end{array}$ & School leavers & CATI (survey) \\
\hline $\begin{array}{l}\text { Fourth wave } \\
2013 \text { (autumn) }\end{array}$ & School leavers & $\begin{array}{l}\text { CAPI/PAPI } \\
\text { (survey and tests) }\end{array}$ \\
\hline
\end{tabular}

\section{Survey duration}

3 class periods testing, 1 period questionnaire (autumn, spring)

40 min. (autumn) + 20 min. (spring)

40 min. (autumn) + 20 min. (spring)

$65 \mathrm{~min}$. testing, $25 \mathrm{~min}$. interview

\section{Selected Potential Research Areas with NEPS Stage 6}

The aim of Stage 6 is to map the trajectories of adolescents' school-to-work transitions in as much detail as possible (including the trajectories of those who never enter or complete vocational training). Providing precise descriptions is a subordinate, albeit important, concern, considering the lack of a comprehensive picture of the diversity of pathways. The primary research goal is to study the causes of the differences in school leavers' transition pathways and outcomes. Defining these causes requires a process-related analysis that examines the interplay between individual factors (adolescents' interests, motivation, and skills), social contexts (parental support, embeddedness in peer groups, social networks), and the given VET programmes and learning environments at the decisive points in individual transitional biographies.

In an ideal-typical way, the transition from school to work involves three distinct processes: (1) adolescents' placement in the VET system (access to vocational training) (2) adolescents' success in a given VET programme (3) labour market entry. Since several years have yet to pass before NEPS participants enter the labour market, we will focus on important areas of research potential for the first two processes.

\section{Placement in the VET system and access to fully qualifying training programmes}

Adolescents' placement in the VET system is known to be heavily influenced not only by their school certificates, but also by their social background and the social resources in their environment, their migrant background, and their

gender. School drop-outs are particularly disadvantaged in this context (Solga 2004, 2008).

Against the backdrop of the opportunity structures defined by these factors, VET placement ultimately results from the interplay between adolescents' occupational aspirations and their strategies for finding an apprenticeship position on the one hand, and the range of available apprenticeship positions in the dual or full-time school-based VET system, as well as schools' and employers' recruitment processes and criteria, on the other. Moreover, the Federal Employment Agency functions as a gatekeeper for a sizeable group of adolescents because of its ability to use its career guidance and placement services, thereby structuring and restricting applicants' opportunities. The Agency does so in an even more decisive way, by categorizing some adolescents as 'suitable' and 'mature enough for VET' (ausbildungsreif) - a precondition for qualifying for career guidance and placement services in the first place - while denying these labels to others.

On the adolescents' side, research may begin by exploring how they perceive the available VET offer and their own chances of accomplishing their training goals, and how they go about their educational decision-making and search strategies. They will not be viewed as isolated actors here, however, since variables such as parental support, school-based career guidance programmes, and VET entry support services, as well as the importance of peer groups, various sources of information, or learning experiences and contacts acquired through part-time jobs and internships, will be available. Finally, additional 'context' information for the occupational search process in ninth grade will be generated by aggregating individual data for the whole class. Furthermore, over the subsequent course 
of NEPS, the short intervals between survey waves will allow us to study the changes in students' search and application behaviour and the ways in which they adapt their goals to what appears feasible.

These data and the information collected on adolescents' skills, motivation, or even healthrelated limitations, will produce indicators for apprenticeship applicants' behaviour and performance. These may be contrasted with the more 'tangible' or observable characteristics that Employment Agency career counsellors, employers, or other training institutions tend to use to assess apprenticeship applicants (i.e. their educational biography, final grades, and social background) for classifying them as 'suitable' or 'not (yet) mature enough for VET'. Observing the interplay of these factors enables us to explore not only which types of adolescents' behaviour, but also which types of selection processes, tend to structure their access to VET positions, and to study the role of regional differences in VET programmes and labour market prospects.

In doing so, we will not only consider fully qualifying VET programmes, but also the prevocational transition system. While the official goal of pre-vocational programmes is to improve applicants' chances of finding a (company- or school-based) apprenticeship position, there has been ongoing scepticism about the actual efficacy of these programmes. One of the reasons why it is difficult to arrive at a well-grounded assessment here is that while participants enrolled in prevocational programmes represent a specifically selected group, the processes on which their selection is based are largely unknown.

The differentiated data on ninth graders provided by NEPS will enable us to study whether and how adolescents enrolled in a variety of programmes are different from one another and, more importantly, whether and how they are different from those who were able to obtain a fully qualifying apprenticeship position right away. This will allow us to analyze whether unequal opportunities to access fully qualifying VET programmes may be traced back to adolescents' initial level of skills and motivation, to regional opportunity structures, or to differences in the ways career counsellors, employers, or other training institutions ascribe certain skills to applicants with different educational biographies.

\section{Dropping out of VET and completing VET programmes successfully}

It is a well-known fact that a sizeable number of apprentices drop out of their training programmes, often as early as in their first year; however, a remarkable share of these drop-outs tends to find a new training opportunity fairly quickly. Again, the NEPS data will allow us to study the interplay between adolescents' skills and other characteristics, their (initial) occupational aspirations (surveyed prior to their apprenticeship search and subsequent dropout), and their training environment, in order to come to a more precise analysis of what influences possible 'ruptures' in VET trajectories and how adolescents deal with these ruptures. Because of its longitudinal design, NEPS will supplement existing studies of VET drop-out rates, which may often explore adolescents' re-entry into the VET system only, and not their final training success or failure. Moreover, NEPS also includes full-time school-based VET programmes, which so far have received little attention. As a result, comprehensive knowledge about VET trajectories that either turn out successfully, are fraught with complications, or end in 'failure' - and their outcomes, for example in terms of labour market success, wellbeing and health, and political participation - will become possible.

Finally, there is a substantial research gap with regard to the acquisition of occupation-specific or cross-occupational competencies in a VET programme. We therefore plan to select a few occupations and try to use tests for measuring occupation-specific skills developed in recent years (Winther and Achtenhagen 2009). Here, our primary concern is to find out whether these extensive testing procedures are at all feasible within NEPS (which is not a specialized study of individual occupations) in order to gather experiences for applying them more broadly during the second funding term. Furthermore, we seek to develop a concept for cross-occupational competencies.

\section{Outlook}

This paper provided an overview on the survey design and the potential for scientific analysis in NEPS Stage 6 'Vocational Education and Training and Transition into the Labour Market'. NEPS Stage 6 has the capacity to provide a database which is capable of answering some of the fundamental questions in relation to VET - not only for Germany, but also in general. Which skills are necessary for a successful 
transition into the labour market, and what is the best way to acquire them? What are appropriate ways for enabling low-achieving youth to enter and complete vocational training? How do cognitive and noncognitive competencies develop in the course of vocational education and training? And what role do they play in relation to other market signals, such as educational certificates or gender, ethnic background, and health?

NEPS uniquely combines an ambitious longitudinal design for capturing life histories, with psychometric tests of cognitive and non-cognitive competencies allowing us to apply advanced longitudinal methods of analysis, such as event history analysis, sequence analysis, or the estimation of random and fixed effects panel models. Due to its design and set-up, NEPS Stage 6 has some major advantages, compared to existing German and international data sets, on the transition from school to work. It is the first data set to enable researchers to investigate how competencies develop and how this development is influenced by the various learning environments that young people are part of and confronted with. Due to the high number of cases and the strategy of oversampling groups that are particularly disadvantaged in the German VET system (low-achieving school leavers, youth with learning disabilities, or migrants), it becomes possible to study the trajectories of these young people, not least to investigate whether the pre-vocational training measures they so often embark on provide opportunities for entering the regular VET system later on, or whether they are more of a 'dead end' where the young people move from one measure to the next. The large sample size of disadvantaged youth also allows intra-group analyses in order to investigate the interplay of individual and institutional factors for resilience or 'success against all odds'. Moreover, the inclusion of a large sample of young people with learning disabilities provides a data set for international scholars to study the competence development and life course trajectories of this largely under-investigated group (a statement that holds true not only for Germany).

Furthermore, NEPS Stage 6 will enable researchers to take into account the multitude of learning environments young people are confronted with at the end of compulsory schooling. This refers not only to the different types of vocational training, where it will be possible to compare dual-system apprenticeships in smaller companies with those in larger companies or with school-based vocational training, but also to the (often very selective) learning environments in pre-vocational training measures. Finally, how learning facilities at home, partners, family, and social networks support or impede learning and competence development, can be studied in more detail.

Yet, it will require a lot of patience before this research potential can be fully exploited. The first survey of ninth graders took place in autumn 2010. In autumn 2011, data collection will start on the transitions to the VET system for the subgroup of those adolescents who leave school after grade nine. The vast majority of pupils, however, will only leave school after completing grade ten (i.e. in 2012), or even after completing grades 12 or 13 (2013/2014). Because of the complex research design of NEPS, data from the first survey wave (ninth grade/2010) will not be available before 2012. Data (and analyses) regarding the first step of ninth and tenth grade graduates (wave 2/2011 and spring wave 2012) may not be expected before late 2013. The data sets will be made available for the scientific community as scientific use files by the Institute for Longitudinal Education Research Bamberg (INBIL). More and updated information can be found on the NEPS webpage:

http://www.uni-bamberg.de/en/neps/

\section{References}

Baethge M. (2000) The German 'Dual System' of Training in Transition: Current Problems and Perspectives. In Berg P. ed. Creating Competitive Capacity: Labor Market Institutions and Workplace Practices in Germany and the United States. Pp 101-118. edition sigma, Berlin.

Baethge $M$, Solga $H$ and Wieck M. (2007) Berufsbildung im Umbruch. Signale eines längst überfälligen Aufbruchs. Friedrich-Ebert-Stiftung, Bonn http://library.fes.de/pdffiles/stabsabteilung/04258/studie.pdf.

Blossfeld HP, Schneider T and Doll J. (2009) Methodological advantages of panel studies. Designing the new National Educational Panel Study (NEPS) in Germany. Journal for Educational Research Online, 1, 1032.

Buchmann M. (1989) The Script of Life in Modern Society: Entry into Adulthood in a Changing World. University of Chicago Press, Chicago. 
Culpepper PD and Finegold D. eds. (1999) The German Skills Machine. Sustaining Comparative Advantage in a Global Economy. Berghahn Books, New York, Oxford.

Culpepper PD and Thelen K. (2008) Institutions and Collective Actors in the Provision of Training: Historical and Cross-National Comparisons. In Mayer KU and Solga H. eds. Skill Formation - Interdisciplinary and Cross-National Perspectives. Pp 21-49. Cambridge University Press, New York.

Dietrich H, Dressel K, Janik F and Ludwig-Mayerhofer W. (2009) Ausbildung im dualen System und Maßnahmen der Berufsvorbereitung. In Möller J and Walwei U. eds. Handbuch Arbeitsmarkt 2009. Pp 317-357. Bertelsmann Verlag, Bielefeld.

Eberhard V, Krewerth A and Ulrich JG. (2006) Mangelware Lehrstelle. Zur aktuellen Lage der Ausbildungsplatzbewerber in Deutschland. BIBB, Bonn.

Estevez-Abe M, Iversen T and Soskice D. (2001) Social protection and the formation of skills: A reinterpretation of the welfare state. In Hall A and Soskice D. eds. Varieties of Capitalism: The Institutional Foundations of Comparative Advantage. Pp 145-183. Oxford University Press, New York.

Herrigel G and Sabel C. (1999) Craft Production in Crisis: Industrial Restructuring in Germany During the 1990s. In Culpepper PD and Finegold D. eds. The German Skills Machine. Sustaining Comparative Advantage in a Global Economy, Pp 77-114. Berghahn Books, New York, Oxford.

Mayer KU and Solga H. eds. (2008) Skill Formation - Interdisciplinary and Cross-National Perspectives. Cambridge University Press, New York.

Powell JJW. (2009) To segregate or to separate? The institutionalization of special education in the United States and Germany. Comparative Education Review, 53, 161-187.

Reich RB. (1991) The Work of Nations: Preparing Ourselves for 21st Century Capitalism. A.A. Knopf, New York.

Solga H. (2004) Increasing risks of stigmatization. Changes in school-to-work transitions of less-educated West Germans. Yale Journal of Sociology, 4, 99-129. http://www.yale.edu/sociology/vis/vis fall 2004.pdf.

Solga H. (2008) Lack of training - Employment opportunities of low-skilled persons from a sociological and microeconomic perspective. In Mayer, KU and Solga H. eds. Skill Formation - Interdisciplinary and Cross-National Perspectives. Pp 173-204. Cambridge University Press, New York.

Streeck W. (1989) Skills and the Limits of Neo-Liberalism. The Enterprise of the Future as a Place of Learning. Work, Employment and Society. 3, 89-104.

von Maurice J, Leopold T and Blossfeld HP. (2009) The National Educational Panel Study: A long-term assessment of competence development and educational careers. Paper presented at the ONS UKCeMGA and NIESR International Conference on Public Service Measurement, November 2009, Cardiff, UK. http://www.uni-bamberg.de/neps/publikationen/

Winther E and Achtenhagen F. (2009) Measurement of vocational competencies. Empirical Research in Vocational Education and Training, 1, 88-106.

\section{Endnotes}

' For example, the German Life History Study (GLHS) collected data retrospectively from several birth cohorts on their educational and employment biographies. The German Socio-economic Panel Study (SOEP), a general public survey carried out every year in Germany since 1984, combines retrospective data on the work and family-related event history with prospective panel data on, amongst others, educational participation as well as job and income mobility.

ii For example, the 'Transition Panel' (Übergangspanel) of the German Youth Institute (DJI) focuses on the transitions of 'disadvantaged' students who have finished the lower school track, tracing their paths into the vocational training system and into the labour market. Furthermore, there is the ULME study (Untersuchung von Leistungen, Motivation und Einstellungen zu Beginn der beruflichen Ausbildung), which investigates the competencies of apprentices in the city of Hamburg at the end of their vocational education, but does not follow them as they enter the labour market. iii OECD studies such as PISA (Programme for International Student Assessment), TIMSS (Third International Mathematics and Science Study), IALS (International Adult Literacy Study), or ALL (Adult Literacy and Life Skills Survey), and cohort studies of several countries either provide competence tests in several domains or focus on specific domains (such as numeracy or reading/language), but are cross-sectional in design and/or do not include multi-time measurements of competencies.

${ }^{\text {iv }}$ For data protection procedures applied in the NEPS, see von Maurice, Leopold and Blossfeld (2009). 